\title{
Measurement and correlation of acoustic emissions and pressure stimulated voltages in rock using an electric potential sensor
}

\author{
J W Archer ${ }^{\text {a }}$, M R Dobbs ${ }^{\text {b }}$, A Aydin ${ }^{\text {a,1 }}$, H J Reeves ${ }^{\text {b }}$ and R J Prance ${ }^{\text {a }}$
}

${ }^{a}$ Sensor Technology Research Centre, School of Engineering and Design, University of Sussex, Brighton, East Sussex, BN1 9QT, UK

${ }^{\mathrm{b}}$ Rock Mechanics and Physics Laboratory, British Geological Survey, Keyworth, Nottinghamshire, NG12 5GG, UK

*Corresponding author: James W Archer (j.w.archer@sussex.ac.uk)

Marcus R Dobbs (ㅍac1@bgs.ac.uk)

Ahmet Aydin (Ahmet.Aydin@fdmgroup.com)

Robert J prance (r.j.prance@sussex.ac.uk)

Helen J Reeves (hjre@bgs.ac.uk)

\begin{abstract}
Previous laboratory based studies have demonstrated pressure stimulated currents and electromagnetic emissions in rock and cement mortar can be used to assess damage. There is some debate whether the current and electromagnetic emission measurement technologies used thus far are viable for field application. The results presented here provide evidence that electric potential sensors are a viable new technology for field monitoring of electrical emissions. Cylindrical specimens of rock were loaded at constant stress or strain rates until failure occurred; strain gauges, piezoelectric transducers and electric potential sensors were used to monitor the strain, acoustic emissions and pressure stimulated voltages. Pressure stimulated voltages were observed in the linear elastic and inelastic deformation regions of loading, suggesting that pressure stimulated voltages are associated with microcracking and macrocracking events.
\end{abstract}

\footnotetext{
${ }^{1}$ Present address: Dr Ahmet Aydin, FDM Group Inc, 14 Wall Street, New York, NY 10005, USA
} 
Keywords: Electric Potential Sensor, pressure stimulated voltage, piezo transducer, acoustic emissions and uniaxial compression.

\section{Introduction}

Sensing technologies are used for monitoring manmade and geological structures and for earthquake detection/prediction and are thus critical for improving the health and safety of humans, buildings and infrastructure [1]. Although there are many existing technologies and research projects aimed at solving these problems, there is no unified solution. Currently, a wide range of sensing technologies are needed to monitor a structure and provide precursory information of imminent failure.

One new method that could complement or replace existing methods is the measurement of electromagnetic emissions, which can be used to monitor damage and provide an indication prior to catastrophic failure of rocks and concrete. Laboratory based studies have demonstrated the existence of weak electromagnetic emissions in various rock lithologies and cement mortar [2-5]. The generation mechanism/s is/are still uncertain but include the electrokinetic effect of moving water [6,7], piezoelectric effect of quartz [6, 8], rock fracture (contact and separation of fresh surfaces) [9], and moving charge dislocations $[10,11]$. Some of these studies have shown that pressure stimulated current (PSC) emissions are related to a change in Young's modulus [12] and variations in PSC are observed beyond the linear elastic limit in marble specimens [13]. PSCs are also associated with high amplitude acoustic emissions (AE) events and high event rates in cement mortar beams [14]. Another method reported electromagnetic emissions during dilating fracture of granite and limestone specimens using electromagnetic emission (EME) antennas [5].

There is a debate as to whether the technologies employed thus far for the detection of PSCs and EMEs are feasible for field use. Currently, benchtop electrometers are used for PSC measurement. These instruments are expensive and designed for the laboratory setting. There are also two inherent problems with PSC measurement using electrometers, firstly the low-level currents generated (in the pico amp range) and secondly the closed loop system configuration relies on pairs of electrodes that are some arbitrary distance apart for the measurement. EME antennas require magnetic and electric field shielding from the outside world to increase the signal to noise ratio of EME from rock specimens and may therefore not be a practical approach for field measurements.

One technology that could resolve many of these issues is the electric potential sensor (EPS) developed and patented by the University of Sussex (UoS) [15]. EPS technology has been successfully implemented for a number of diverse field applications, including imaging active electrical circuits [16], 
monitoring human electrophysiology [17] and nuclear magnetic resonance signal acquisition [18]. In addition, recent work carried out by UoS has demonstrated the detection of pressure stimulated voltages (PSVs) in various rock lithologies, where aluminum control samples were used to demonstrate that PSVs originate from the rocks and not from the equipment used or the local environment $[3,19]$.

Measuring PSV using EPS technology is a viable alternative to PSC detection. The inherent advantage for measuring PSVs is that the voltages occurring in the order of Volts yield a much better signal to noise ratio than the associated currents therefore meaning that electromagnetic shielding is unnecessary. Other major benefits of the technology include: (1) made from conventional low cost semiconductor components, (2) non-invasive measurement due to the ultra-high input impedance nature of the device (input capacitance $<10^{-15} \mathrm{~F}$ and input resistance $>10^{13} \Omega$ ), (3) broad bandwidth ranging from quasi DC to $>100 \mathrm{MHz}$, (4) capable of single ended (ground referenced) operation. EPS could be the first viable sensor technology capable of detecting electrical emissions from rock outside the laboratory environment and could upscale to sensor array formats for the monitoring of large structures and areas.

The work described here characterizes PSV emissions with stress, strain and AE during the uniaxial loading of quartz-rich syeno-granite (granite) and non-quartzose halite-stone (halite).

\section{Materials and Methods}

\subsection{Rock lithology and specimen preparation}

Right circular cylinder specimens, $100-137 \mathrm{~mm}$ in length and approximately $50 \mathrm{~mm}$ in diameter, were extracted from large block samples $(5-20 \mathrm{~kg})$. An expert mineralogist from the British Geological Survey determined the lithology type [20-22] and mineral composition by point counting, halite specimen (62\% Halite, $38 \%$ Anhydrites/clays) and syeno-granite (45\% Quartz; $36 \%$ Alkali feldspar; $17 \%$ Plagioclase feldspar; $1 \%$ Sericite $<1 \%$ Muscovite). To eliminate the electrokinetic effect of water movement, the specimens were dried in a fan-assisted oven at $105{ }^{\circ} \mathrm{C}$ to $110{ }^{\circ} \mathrm{C}$ until they achieved a constant mass, typically 24 - 48 hours. The specimens were then placed in a desiccator that contained dry self-indicating silica gel and left to cool to room temperature before being instrumented and tested.

\subsection{Testing Procedure}

Both specimens were instrumented with two capacitively coupled electrodes placed diametrically opposite each other, positioned $10 \mathrm{~mm}$ from the bottom and the top of the specimen, respectively. The 
$25 \mathrm{~mm}$ x $25 \mathrm{~mm}$ copper electrodes were electrically isolated from the specimen using a $30 \mathrm{~mm}$ x $30 \mathrm{~mm}$ adhesive Kapton ${ }^{\circledR}$ polyimide film between the specimen and electrode to ensure no current was drawn (non-invasive measurement). An EPS was directly coupled to each electrode structure and held in place with elastic bands around the circumference of the specimen. Two wide band $(100-1000 \mathrm{kHz})$

piezoelectric transducers (WSA SN AE18) supplied by Physical Acoustics Corporation were fitted to the side of stainless steel platens by means of brass housings.

A direct contact circumferential strain gauge (MTS 632.12-20) was fitted around the center of the specimen and two direct contact axial strain gauges (MTS 632.11-90) were attached on opposite sides of the specimen. The strain gauges utilize Wheatstone bridge circuits and are able to measure strain accurate to $\pm 0.0001 \mathrm{~mm} / \mathrm{mm}$. Two single sided PCB plates were positioned between the specimen and each $\mathrm{AE}$ platen, to earth the platens and load frame and to electrically isolate the specimen. Load was measured using a $1 \mathrm{MN}$ capacity force transducer (MTS 661.98) accurate to $\pm 0.34 \%$ of the load. The detailed view of the apparatus and sensor positions are shown in figure 1. 


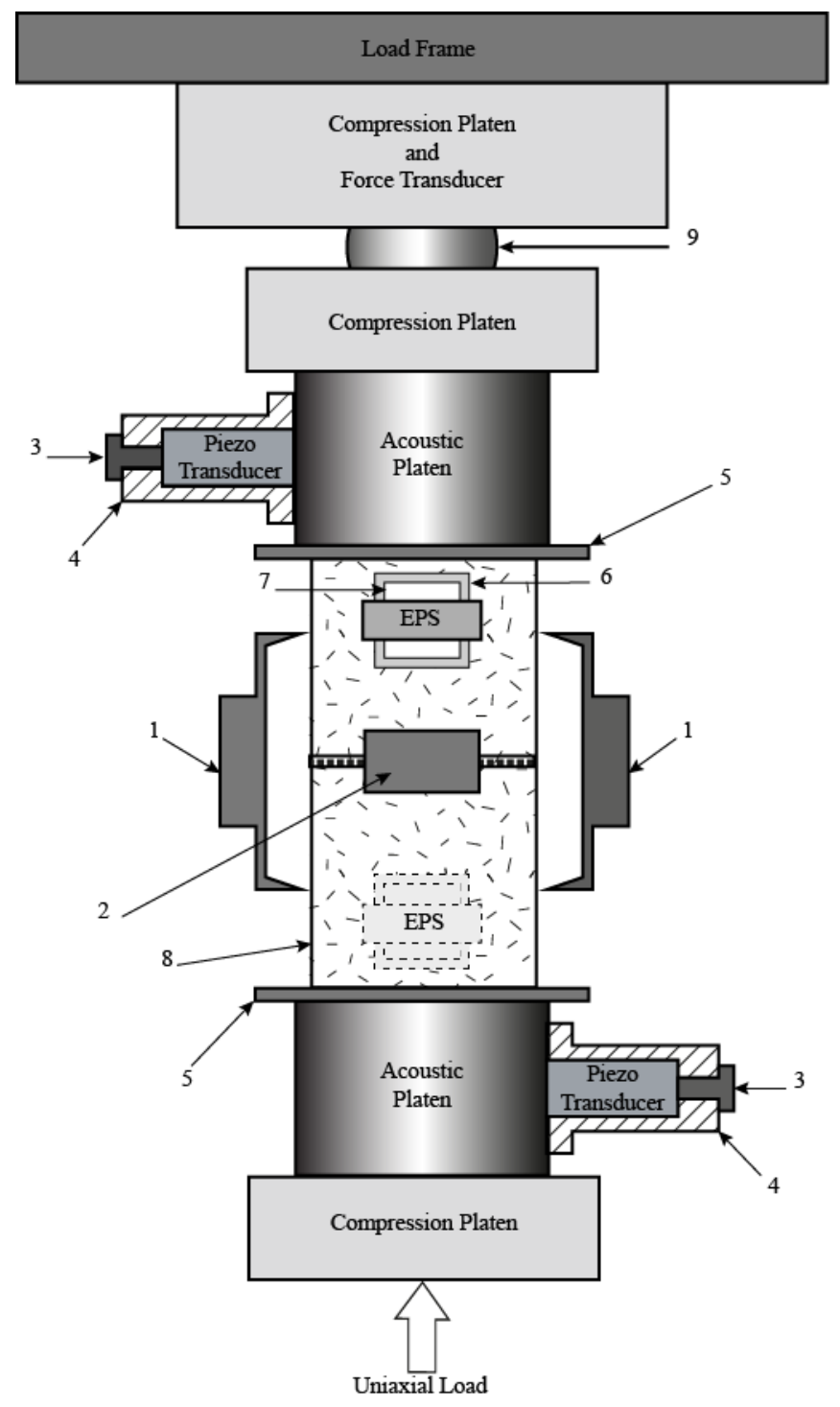

Figure 1. Experimental test configuration and instrumentation. (1) Axial direct strain gauge, (2) Circumferential strain gauge, (3) piezo transducer securing screw, (4) brass housing for piezo transducer, (5) electrically insulating plate, (6) Kapton ${ }^{\circledR}$ polyimide film, (7) copper electrode, (8) cylindrical rock specimen, (9) radial loading joint.

A 4.6 MN capacity servo-controlled hydraulic load frame (MTS 815) was used to apply load. Prior to commencing the experiments, a fixed AE threshold was individually determined for each specimen. The AE threshold was determined as the minimum $\mathrm{dB}$ threshold at which no hits were detected when a $1 \mathrm{kN}$ load was applied and held on the specimen over a duration of approximately 10 minutes. The difference in threshold levels is a reflection of the seismic attenuation within the samples, which is greater in the Halite and hence the lower AE threshold to eliminate noise. Specimens were subject to a single continuous increase in stress until failure occurred, load was applied to the granite sample at a constant axial strain rate of $6.5^{*} 10^{-6} \mathrm{~s}^{-1}$ and to the halite sample at a constant axial force rate of $0.18 \mathrm{kNs}^{-1}$, 
such that failure occurred in 4-5 minutes. Peak stress and AE threshold data for each experiment are shown in table 1.

Table 1. Loading and threshold data for halite and granite samples.

\begin{tabular}{llll}
\hline \hline Lithology & $\sigma_{\text {peak }^{a}}$ & Failure $^{\mathrm{b}}$ & $\begin{array}{l}\mathrm{AE} \\
\text { threshold }\end{array}$ \\
\hline Halite-stone & $21.75 \mathrm{MPa}$ & $230.6 \mathrm{~s}$ & $26 \mathrm{~dB}$ \\
Syeno-Granite & $122.3 \mathrm{MPa}$ & $322.9 \mathrm{~s}$ & $35 \mathrm{~dB}$ \\
\hline
\end{tabular}

\footnotetext{
${ }^{\mathrm{a}}$ The maxium stress reached before structual failure

${ }^{\mathrm{b}}$ The time duration before structural failure
}

\subsection{Data Acquisition}

Each piezo transducer was connected to a Physical Acoustics Corporation acquisition system (PCI-2) via a $40 \mathrm{~dB}$ preamp and the associated AEwin software performed the signal conditioning AE hit/event detection. The EPSs were configured with a gain of 5, the output signals from the sensors were notch filtered at $50 \mathrm{~Hz}$ to remove the effects of the ambient electric field and digitalized at a sampling frequency of $1.5 \mathrm{kSs}^{-1}$ using a National Instruments analogue to digital converter (NI PXI-6124). The EPS data were acquired using a custom National Instruments virtual instrument on a computer (NI PXIe1071). The strain and load data were acquired using MTS MultiPurpose TestWare software on a second PC connected to the force transducer and strain gauges. All three acquisition systems were synchronized by the load frame controller (MTS FlexTest 60) at the start of each experiment.

\subsection{Data Analysis}

All data were binned at 0.25 seconds prior to analysis. The RMS voltage produced in the piezo transducer associated with each AE event was normalized and used for cross-correlation analysis with the normalized differential measurement of RMS PSV from the rock. The number of AE events were computed by the AEwin software and the PSV events were defined as a peak in RMS voltage greater than half a standard deviation from the mean RMS voltage. This procedure extracts the relatively high amplitude and frequency transient electric potential signals (expected to be related to cracking events) from the low frequency and amplitude baseline noise (expected to arise from the piezo electric effect of quartz) for cross-correlation analysis with AE data. Due to limited computational power it was not practical to calculate the number of PSV events from the raw data acquired at $1.5 \mathrm{MSs}^{-1}$ so the PSV events were defined after binning the data. The number of events is thus perceived to be much lower for 
the PSV compared to AE, which is a computational artifact. However, the event rate, i.e. the slope of the cumulative number of events plotted in figures 2 and 5 , remains accurate.

\subsection{Defining the stages of rock deformation}

The resulting stress strain curves have been divided into five recognized stages of deformation [23-25]. Stage 1) pre-existing microcrack and pore closure; characterized by strain-hardening behavior (concave up); Stage 2) recoverable elastic deformation; characterized by linear axial and volumetric deformation with very little or no AE activity; Stage 3) partially recoverable elastic deformation and stable microcrack propagation; characterized by linear axial deformation, onset of volumetric dilatency and increase in AE activity. Stage 4) non-recoverable pre-peak inelastic deformation resulting from unstable microcrack propagation and coalescence; characterized by strain-hardening behavior (concave down), rapid volumetric dilation and acceleration in AE rate and amplitude. Stage 5) non-recoverable post-peak inelastic deformation resulting from unstable macrocrack and shear plane development; characterized by strain-softening behavior (concave down), surge in volumetric dilation and AE rate and amplitude.

\section{Results}

\subsection{Syeno-granite}

Figure 2 shows data from the ramp-to-destruction (RTD) loading of the granite sample. During Stage 1 there is an increase in the AE event rate, however the AE events are relatively small and there is little to no PSV activity [25]. In Stage 2 there is little to no AE or PSV activity with the exception of a single high magnitude event at $0.95^{*} 10^{-3} \mathrm{~mm} / \mathrm{mm}$ in the AE and at $0.98 * 10^{-3} \mathrm{~mm} / \mathrm{mm}$ in the PSV. There is a simultaneous increase in both the AE and PSV at the beginning of Stage 3. Initially, the frequency of both the AE and PSV events appears to increase until $1.50^{*} 10^{-3} \mathrm{~mm} / \mathrm{mm}$, then becomes stable until the end of the stage. Conversely, the magnitude of the events is relatively consistent at the beginning of the stage and then begin to noticeably increase from $1.676^{*} 10^{-3} \mathrm{~mm} / \mathrm{mm}$ for the AE and PSV. During Stage 4 the pattern from the previous stage initially continues before a clear increase in both the frequency and magnitude of both the AE and PSV events from $1.94 * 10^{-3} \mathrm{~mm} / \mathrm{mm}$ is detected. There is a simultaneous surge in both AE and PSV from the beginning and throughout Stage 5. The highest frequency and magnitude in AE and PSV events are observed during this stage. 


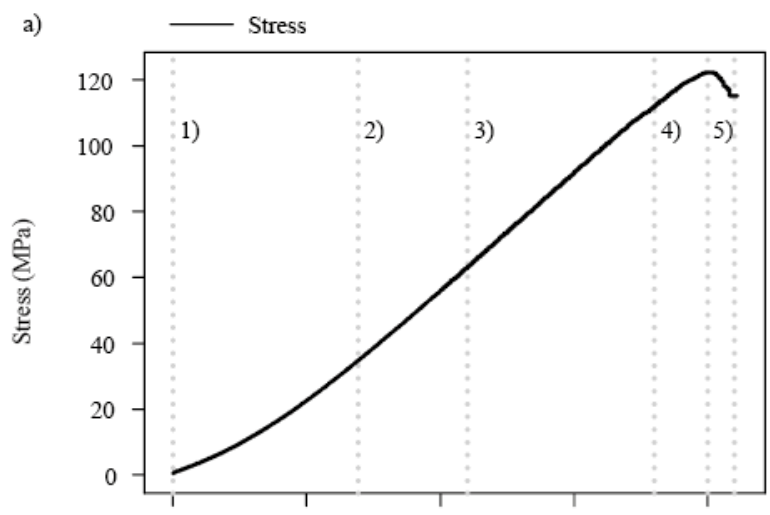

b) $\quad-\mathrm{AE}$

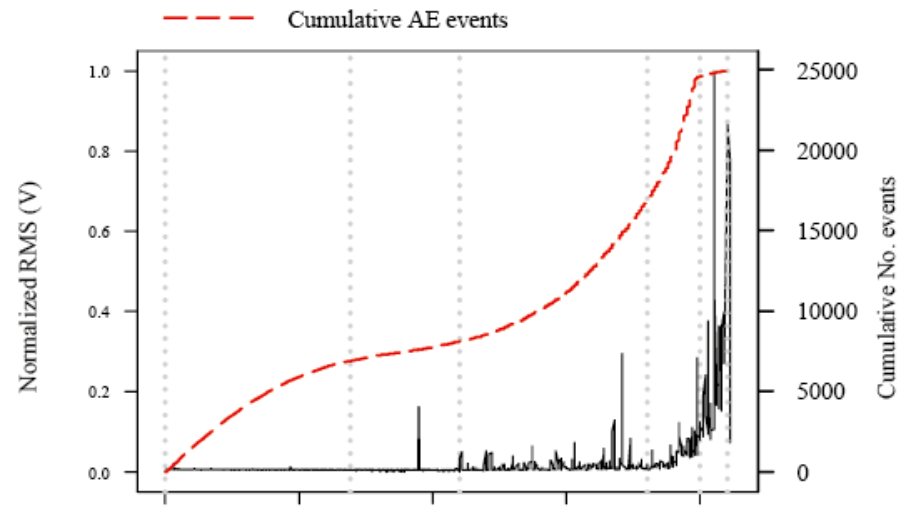

c) PSV - - Cumulative PSV events

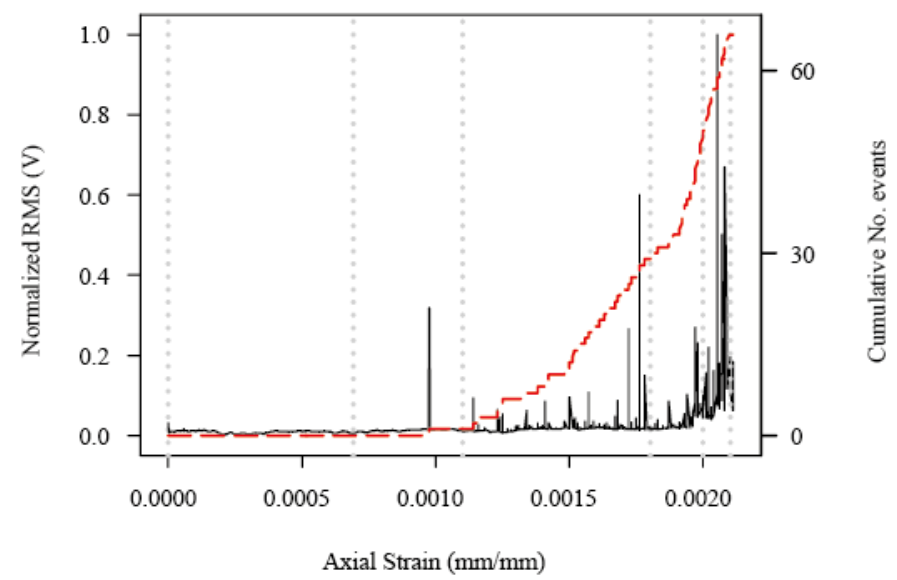

Figure 2. Experimental data from the RTD loading of a granite sample: 1) microcrack and pore closure, 2) recoverable linear elastic deformation, 3) partially recoverable linear elastic deformation and microcrack initiation, 4) non-recoverable pre-peak strain-hardening deformation, 5) non-recoverable postpeak strain-softening deformation. a) applied stress; b) normalized piezoelectric transducer RMS voltage and cumulative number of AE events; and c) normalized PSV RMS voltage and cumulative number of PSV events. 
The cross-correlation analysis for the entire test confirms that the PSV activity correlates with $\mathrm{AE}$, the maximum probability of correlation (0.66) occurs when AE events lag PSV events by $0.75 \pm$ 0.25 seconds. Figure 3 shows the cross-correlation probability at varying lead and lag times; there is a well-defined narrow peak in probability.

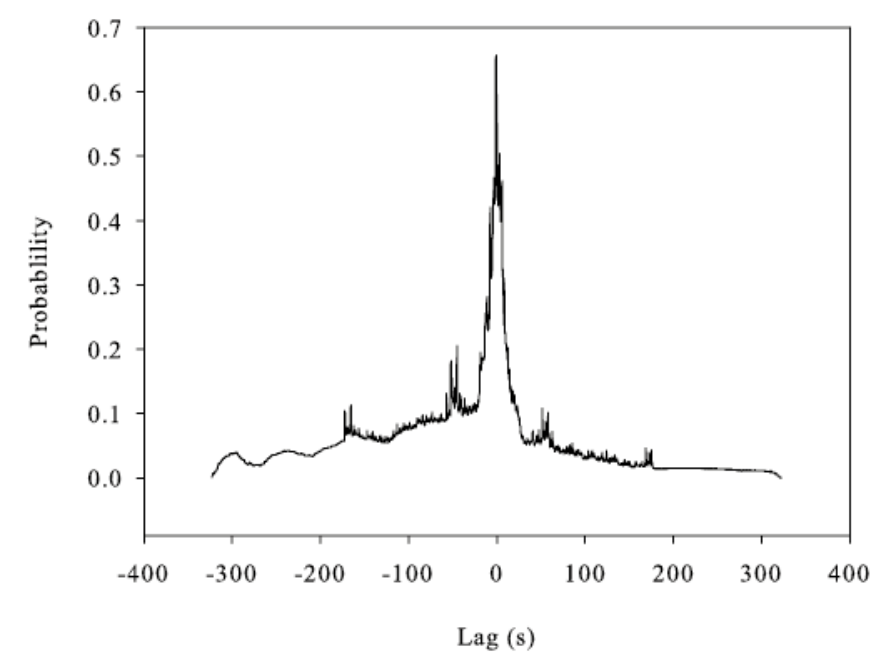

Figure 3. Experimental data from the RTD loading of a granite sample Stage 1 to 5. A negative lag time indicates AE events lag behind PSV events and positive lag time indicates PSV events lag behind AE events at different probabilities of correlation.

The cross-correlation data for the individual stages of loading for granite is visualized in figure 4 . During Stage 1 there is no significant cross-correlation between AE and PSV because there is little to no AE and PSV activity at this stage of loading. There is a single event in both PSV and AE during Stage 2, where the AE event occurs before the PSV event. This trend continues into Stage 3 with AE events occurring before PSV events, the cross-correlation plots for both stages have well defined and significant peaks in probability (>0.7). Stage 4 and 5 differ from the previous stages because PSV events occur before AE events. The probability of correlation is high (>0.7) and there are defined peaks in probability in the cross-correlation plots. The cross-correlation data for granite can be found in table 2 . 

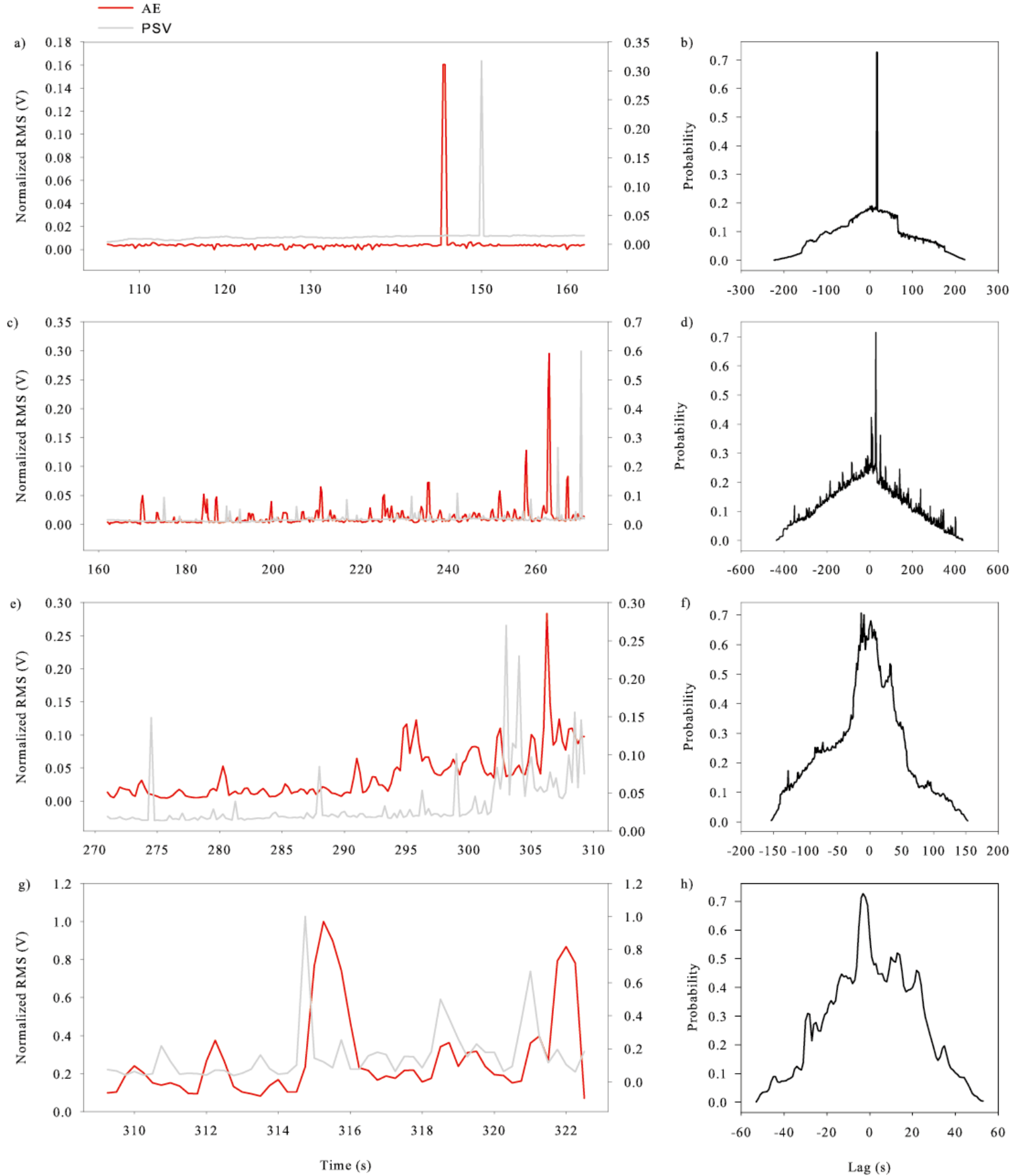

Figure 4. Experimental data from the RTD loading of a granite sample during Stage 2 to 5. Graphs on the left side are time-based plots of piezo transducer and PSV normalized RMS voltage. Graphs on the right side are cross-correlation data showing the probability of correlation between AE and PSV at varying lag times. A negative lag time indicates AE lags behind PSV and a positive lag time indicates PSV lags behind AE. Where graphs a) and b) represent Stage 2, graphs c) and d) represent Stage 3, graphs e) and f) represent Stage 4 and graphs g) and h) represent Stage 5. 


\subsection{Halite-stone}

The RTD loading data of the halite specimen is shown in figure 5. Stage 1 is not observed in the halite specimen. Stage 2 and 3 have been combined because the volumetric and axial stress strain relationships deviate from linearity almost simultaneously. In Stage 2/3 low amplitude AE and PSV activity is observed up until the end of the stage $\left(0.56^{*} 10^{-3} \mathrm{~mm} / \mathrm{mm}\right)$. There is a small sharp increase in PSV at the beginning of Stage 4 and a steady increase in AE and PSV event amplitude up until $13.13 * 10^{-3} \mathrm{~mm} / \mathrm{mm}$ at which point there is a sudden surge in amplitude for the rest of the stage. The frequency of AE and PSV events decreases throughout Stage 4 and 5, though AE shows a more exponential rate of decline than PSV. The AE event amplitude continues to increase towards its maximum level and the PSV amplitude events are consistently very high throughout Stage 5. 


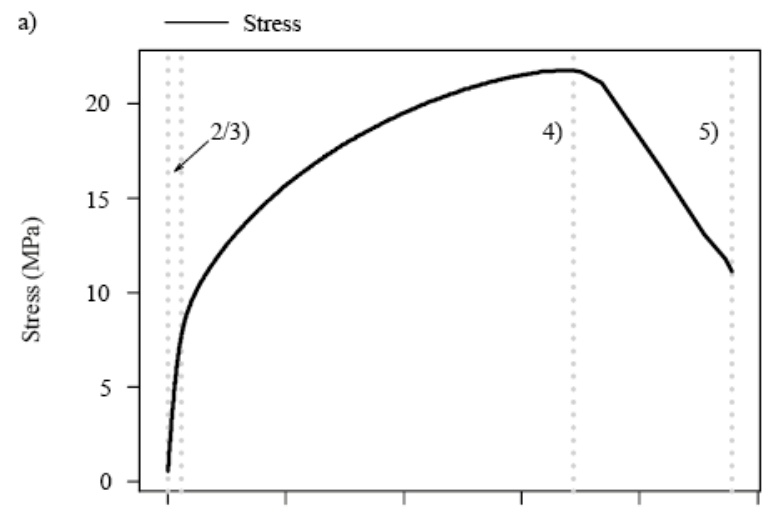

b) $\quad \mathrm{AE}$

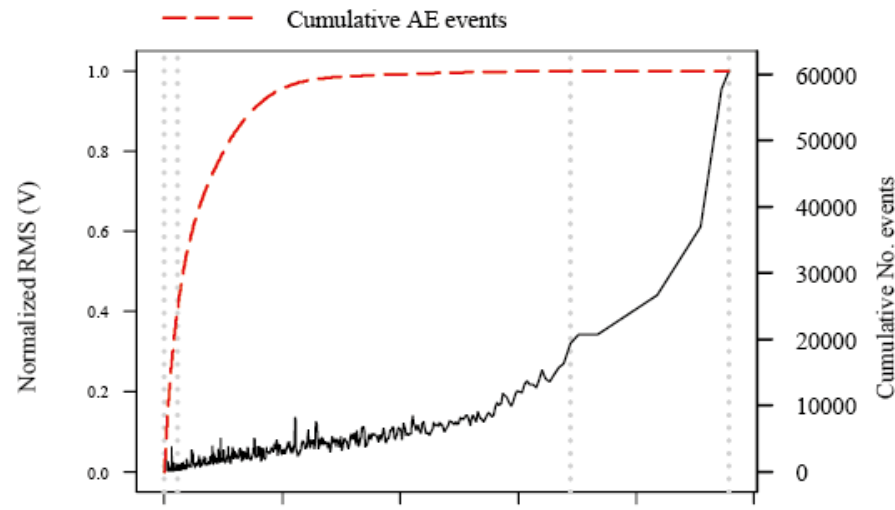

c)

PSV

$---\quad$ Cumulative PSV events

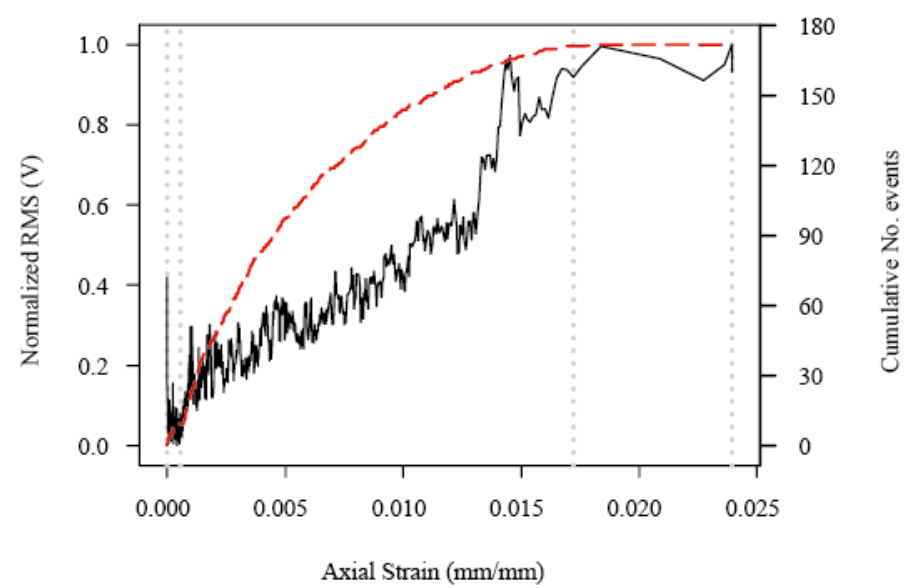

Figure 5. Experimental data from the RTD loading of a halite sample: 2) recoverable linear elastic deformation, 3) partially recoverable linear elastic deformation and microcrack initiation, 4) nonrecoverable pre-peak strain-hardening deformation, 5) non-recoverable post-peak strain-softening deformation. a) applied stress; b) normalized piezoelectric transducer RMS voltage and cumulative number of AE events; and c) normalized PSV RMS voltage and cumulative number of PSV events. 
The cross-correlation between AE and PSV for the entire test was calculated to have a maximum probability of 0.86 at a lag time of $0 \pm 0.25$ seconds. The cross-correlation is shown in figure 6 . The statistical data for the halite experiment are summarized in table 2.

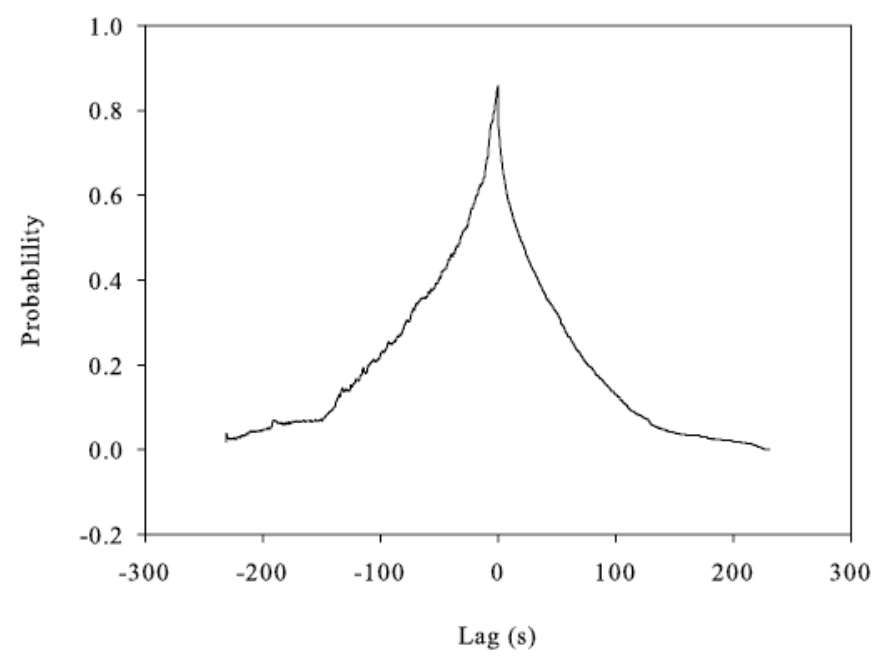

Figure 6. Experimental data from the RTD loading of a halite sample Stage $2 / 3$ to 5 . A negative lag time indicates AE events lag behind PSV events and positive lag time indicates PSV events lag behind AE events at different probabilities of correlation.

The cross-correlation analysis for the individual stages of the loading of the halite experiment is shown in figure 7. There is not a defined Stage 1 and thus no cross-correlation analysis could be computed for this loading stage. A strong correlation > 0.6 with PSV occurring before AE events can be observed for Stage 2/3. The cross-correlation does not have a well-defined peak in probability compared to the overall and Stage 4 cross-correlation plots shown in figures 6 and 7 respectively. The cross-correlation for Stage 4 has a well-defined peak in probability of correlation $>0.9$, and AE and PSV events occur simultaneously during this stage. Stage 5 occurs over a short time frame resulting in only 7 data points which is an insufficient number for an accurate cross-correlation. 

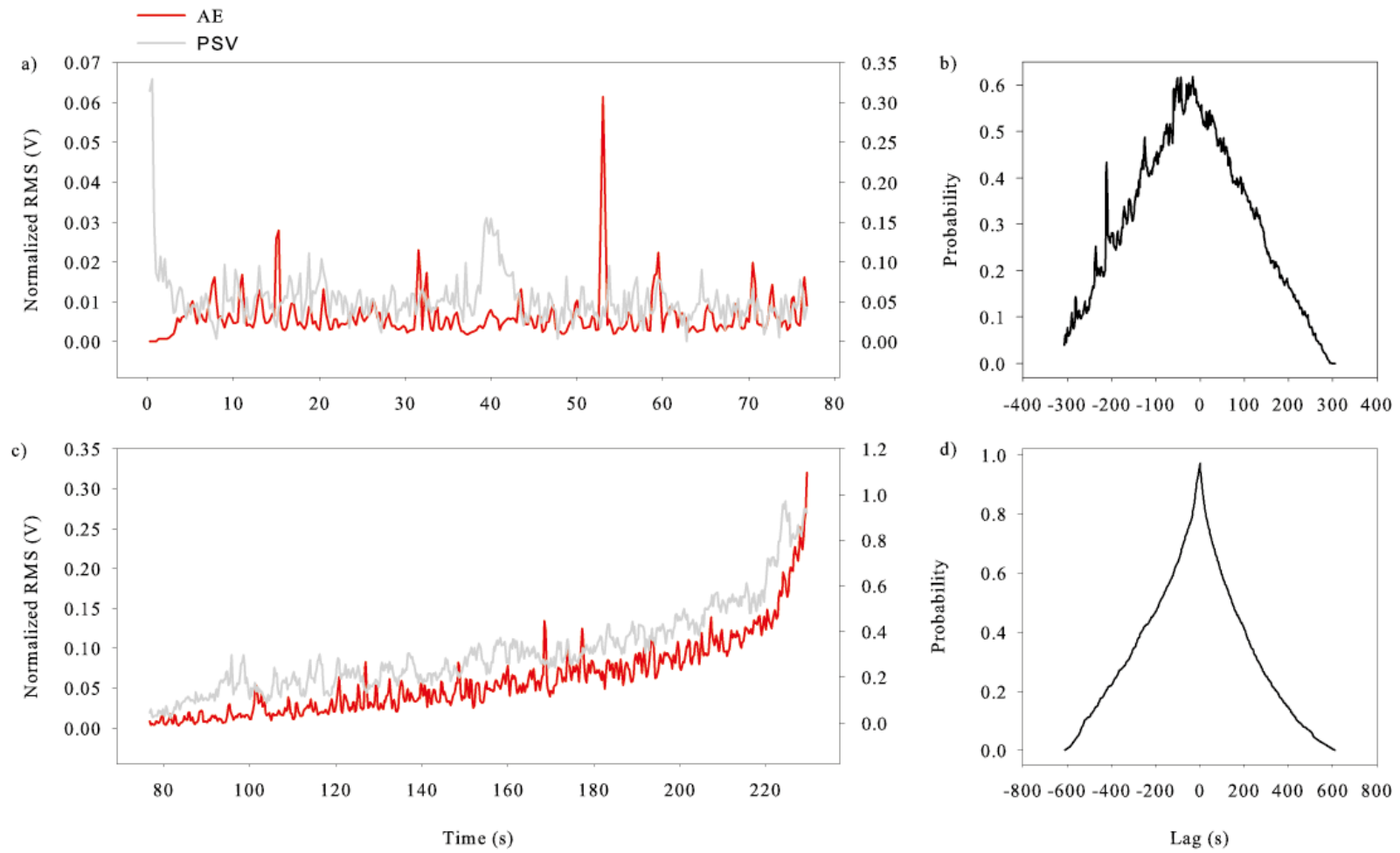

Figure 7. Experimental data from the RTD loading of a halite sample during Stage $2 / 3$ and 4 . Graphs on the left side are time-based plots of piezo transducer and PSV normalized RMS voltage. Graphs on the

right side are cross-correlation data showing the probability of correlation between AE and PSV at varying lag times. A negative lag time indicates AE lags behind PSV and a positive lag time indicates PSV lags behind AE. Where graphs a) and b) represent Stage 2/3 and graphs c) and d) represent Stage 4.

\subsection{Analysis and discussion of results}

Both the halite and the granite experiments bear similar maximum AE amplitudes of $82.25 \mathrm{~dB}$ and $95.25 \mathrm{~dB}$, respectively. This was not the case with regards to the PSV maximum amplitudes, measuring $0.35 \mathrm{mV}$ and $7.1 \mathrm{mV}$ RMS, respectively. The difference in PSV amplitudes is a lithological effect; for both lithologies the PSV emissions were in the range of $\mathrm{mV}$, providing a good signal-to-noise compared PSC measurement.

PSV emissions began to occur during Stage 3 (partially recoverable elastic deformation) in both experiments. Previously, PSCs have only been observed beyond the elastic limit (Stage 4) of marble samples [13]. PSV and AE activity occurs simultaneously ( $\pm 0.25 \mathrm{~s})$ during the halite experiment. In contrast, PSV events overall occur before AE activity by $0.75 \pm 0.25 \mathrm{~s}$ in the granite experiment. Previous studies have shown that PSC peaks arise approximately $1 \mathrm{~s}$ before AE events during the uniaxial loading of cement mortar specimens [14]. 
The wider peak in probability for the cross-correlation of halite shown in figure 6 suggests a significant correlation between overall PSV and AE activities. The narrow peak in probability for the cross-correlation of granite shown in figure 3 implies significant correlation between individual transient spikes in PSV and AE.

All of the cross-correlation plots for the individual stages of loading for both granite and halite have well defined peaks in probability apart from Stage 4 in granite and Stage 2/3 in halite which show more variability. The linear regression is also high for the PSV and AE cumulative number of events for each experiment $\left(r^{2}>0.9\right)$. The cross-correlation and linear regression values are shown in table 2 .

Table 2. Summary of statistical data for halite and granite.

\begin{tabular}{|c|c|c|c|c|c|c|}
\hline & Stage 1 & Stage & Stage 3 & Stage 4 & Stage 5 & Entire test \\
\hline \multicolumn{7}{|l|}{ Halite-stone } \\
\hline Coef $^{a}$ & Stage & \multicolumn{2}{|r|}{0.6186} & 0.97 & Insuficent & 0.86 \\
\hline $\mathrm{Lag}^{\mathrm{b}} \pm 0.25 \mathrm{~s}$ & undefined & \multirow{2}{*}{\multicolumn{2}{|c|}{$-4 s$}} & $0 \mathrm{~s}$ & No. data & $0 \mathrm{~s}$ \\
\hline Regression $^{\mathrm{c}}$ & & & & & points & $r^{2}=0.94$ \\
\hline \multicolumn{7}{|c|}{ Syeno-Granite } \\
\hline Coef $^{a}$ & No & 0.73 & 0.72 & 0.71 & 0.73 & 0.66 \\
\hline $\mathrm{Lag}^{\mathrm{b}} \pm 0.25 \mathrm{~s}$ & significant & $4.25 \mathrm{~s}$ & $7.25 \mathrm{~s}$ & $-3.25 \mathrm{~s}$ & $-0.75 \mathrm{~s}$ & $-0.75 \mathrm{~s}$ \\
\hline Regression $^{\mathrm{c}}$ & correlation & & & & & $r^{2}=0.9$ \\
\hline
\end{tabular}

a The maximum cross-correlation probability between PSV and piezo transducer RMS voltage.

${ }^{\mathrm{b}}$ The lag time between PSV and AE events at the maximum probability of correlation. A negative lag time indicates that AE lags behind PSV events and a positive lag time indicates PSV lags behind AE events. ${ }^{\mathrm{c}}$ The $\mathrm{r}^{2}$ value represents the linear regression between cumulative PSV events and cumulative AE events.

As PSV emissions were observable during the halite experiment and both specimens were oven-dried prior to testing, the PSV generation cannot be entirely due to the piezoelectric effect of quartz, or the electrokinetic effect of moving water. EPSs appear to be sensitive to PSV activity within Stage 3, 4 and 5 in granite and throughout the loading of halite. The PSV event detection worked successfully by extracting transient spikes from baseline noise in the same way as the AE system removes ambient vibrations. This is evident because little to no PSV events were resolved in the granite experiment during Stage 1 and 2 where there are little to no transient spikes in PSV. Therefore, transient spikes in PSV occurring in the latter stages are likely to be associated with inelastic deformation. The baseline noise 
observed in Stage 1 and 2 of granite deformation are expected to be associated with the piezo electric effect of quartz.

The contribution of the piezoelectric effect as a source mechanism for the changes in PSV observed, and to the variation in lag time, is not considered likely for three reasons: 1) During Stage 2 of granite deformation no significant AE or PSV changes are observed, the absence of transient spikes in PSV indicates that the piezoelectric effect is not the source; 2) differences in lead and lag between AE and PSV are also observed in the data from the halite specimen which contains no quartz.

A likely explanation for the difference in lead and lag of AE and PSV at different stages of deformation is that multiple generating mechanisms exist, and that the dominance of these mechanisms changes depending on the stage of deformation and lithology type - as is the case with

AE-generating-mechanisms. For example it is generally observed in crystalline igneous rocks that pore collapse and micro-crack closure are the dominant sources of AE during Stage 1 of deformation; axial cracking the dominant source during Stage 3; and shear cracking the dominant source during Stage 4 and 5 [25]. For PSV-generating- mechanisms it appears that there is at least one mechanism that precedes cracking (as indicated by PSV leading AE in Stages 2/3 of halite deformation and Stages 4 and 5 of granite deformation), and at least one more that is either synchronous with, or is preceded by cracking (as indicated by AE leading PSV in Stage 2 and 3 of granite deformation and the synchronous AE and PSV observed in Stage 4 of the halite deformation. The difference between whether the PSV and AE are simultaneous or whether the AE precedes PSV may be a lithological effect.

\section{Conclusions}

In this paper a uniaxial loading experiment carried out to investigate the correlation between $\mathrm{AE}$ events and PSV activity in quartz-rich syeno-granite and non-quartzose halite-stone has been presented. Based on the results and discussion the following conclusions can be established:

1. The experiments demonstrate a very strong positive correlation between AE and PSV in both the non-quartzose halite and quartz rich granite uniaxial loading experiments.

2. Changes in PSV that occur at the same time or follow AE (and therefore after cracking) may be due to stress redistribution and/or charge redistribution due to formation of new, charged, fracture surfaces. Charge redistribution may be associated with an accumulation of AE events, rather than single events and thus not be instantaneous. The rate of charge redistribution may also be affected by mineralogy and would therefore account for the differences observed between halite and granite. 
3. Changes in PSV that precede AE (and therefore cracking) may be due to stress accumulation and be occurring at the atomic-scale. This would be consistent with the moving charge dislocation mechanism .

4. The transition from lead to lag of AE to PSV igneous rocks would be a very useful indicator of the deformation stage and could potentially be a significant failure precursor signal. Further investigation is required in order to determine whether this phenomenon is present in other lithology types and whether these observations could be recreated using the same technology in field studies.

5. The strong correlation between AE and PSV emissions provides good evidence that EPS could be used as a cost effective complementary technology, and possibly even an alternative, to piezo transducers. First generation EPSs are now commercially available in the form of a monolithic chip (EPIC) from Plessey Semiconductors Ltd for biomedical applications. The development of EPS for PSV detection could follow the same course to create an advanced, cost effective, tool for monitoring and predicting deformation and failure in rock.

6. EPS may be applicable to a number of fields including monitoring and predicting earthquakes and landslides and for the structural health monitoring of manmade subsurface structures such as tunnels, caverns and basements.

\section{Acknowledgments}

The authors would like to thank all colleagues involved at the British Geological Survey and the University of Sussex for their input to the work, in particular D.A. Gunn, L.P. Field and S.J. Holyoake. This paper is published with the permission of the Executive Director of the British Geological Survey (NERC).

\section{References}

Journal articles:

[1] Sohn H, Farrar CR, Hemez FM, Shunk DD, Stinemates DW, Nadler BR, et al. A Review of Structural Health Monitoring Literature: 1996-2001. Los Alamos National Laboratory; 2004.

[2] Anastasiadis C, Triantis D, Hogarth C. Comments on the phenomena underlying pressure stimulated currents in dielectric rock materials. Journal of Material Science. 2007;42:2538-42.

[3] Aydin A, Prance RJ, Prance H, Harland CJ. Observation of pressure stimulated voltages in rocks using an electric potential sensor Applied Physics Letters. 2009;95:124102 - -3. 
[4] Kyriazopoulos A, Anastasiadis C, Triantis D, Brown CJ. Non-destructive evaluation of cement-based materials from pressure-stimulated electrical emission - Preliminary results. Construction and Building Materials. 2011;25:1980-90.

[5] Zhu T, Zhou J, Wang H. Electromagnetic emissions during dilating fracture of a rock. Journal of Asian Earth Sciences. 2013;73:252-62.

[6] Eccles D, Sammonds PR, Clint OC. Laboratory studies of electrical potential during rock failure. International Journal of Rock Mechanics and Mining Sciences. 2005;42:933-49.

[7] Ishido T, Mizutani H. Experimental and theoretical basis of electrokinetic phenomena in rock-water systems and its applications to geophysics. Journal of Geophysical Research: Solid Earth. 1981;86:1763-75.

[8] Nitsan U. Electromagnetic emission accompanying fracture of quartz-bearing rocks. Geophysical Research Letters. 1997;4:333-6.

[9] Yamada I, Masuda K, Mizutani H. Electromagnetic and acoustic emission associated with rock fracture. Physics of the Earth and Planetary Interiors. 1989;57:157-68.

[10] Stavrakas I, Anastasiadis C, Triantis D, Vallianatos F. Piezo Stimulated Currents in marble samples: Precursory and concurrent-with-failure signals. Natural Hazards and Earth System Sciences. 2003;3:243-47.

[11] Vallianatos F, Tzanis A. Electric current generation associated with the deformation rate of a solid: Preseismic and coseismic signals. Physics and Chemistry of the Earth. 1998;23:933-8.

[12] Triantis D, Stavrakas I, Anastasiadis C, Kyriazopoulos A, Vallianatos F. An analysis of pressure stimulated currents (PSC), in marble samples under mechanical stress. Physics and Chemistry of the Earth, Parts A/B/C. 2006;31:234-9.

[13] Stavrakas I, Triantis D, Agioutantis Z, Maurigiannakis S, Saltas V, Vallianatos F, et al. Pressure stimulated currents in rocks and their correlation with mechanical properties. Natural Hazards and Earth Systems Sciences. 2004;4:563-7.

[14] Stergiopoulos C, Stavrakas I, Hloupis G, Triantis D, Vallianatos F. Electrical and Acoustic Emissions in cement mortar beams subjected to mechanical loading up to fracture. Engineering Failure Analysis. 2013;35:454-61.

[15] Prance RJ, Debray A, Clark TD, Prance H, Nock M, Harland CJ, et al. An ultra-low-noise electrical-potential probe for human-body scanning. Measurement Science and Technology. 2000;11:291.

[16] Prance RJ, Clark TD, Prance H, Clippingdale A. Non-contact VLSI imaging using a scanning electric potential microscope. Measurement Science and Technology. 1998;9:1229.

[17] Harland CJ, Clark TD, Prance RJ. Electric potential probes - new directions in the remote sensing of the human body. Measurement Science and Technology. 2002;13:163.

[18] Prance RJ, Aydin A. Acquisition of a nuclear magnetic resonance signal using an electric field detection technique. Applied Physics Letters. 2007;91:044103.

[19] Aydin A, Dobbs MR, Reeves HJ, Kirkham MP, Graham CC. Stress induced electric field measurements of different rock lithology using the Electric Potential Sensor. In: L.J. Pyrak-Nolte AC, W. Dershowitz, J. Morris , J. Rostami, editor. 47th US Rock Mechanics/Geomechanics Symposium. San Francisco , USA2013.

[20] Gillespie MR, Styles MT. BGS Rock Classification Scheme Volume 1. British Geological Survey; 1999. 
[21] Hallsworth CR, Knox RWOB. BGS Rock Classification Scheme Volume 3. British Geological Survey; 1999.

[22] Streckeisen A. To each plutonic rock its proper name. Earth-Science Reviews. 1976;12:1-33.

[23] Brady BHG, Brown ET. Rock Mechanics for underground mining: Springer Netherlands; 2004.

[24] Farmer IW. Engineering Behaviour of Rocks. London: Chapman and Hall Ltd; 1983.

[25] Paterson MS, Wong T-F. Experimental Rock Deformation -in the Brittle Field Springer, Berlin; 2005. 